\title{
Quantitative Evaluation of Compounded Errors During Insulin Administration - A Multicentric Brazilian Study
}

\author{
Andrea Gallo ${ }^{1}$, Augusto Pimazoni-Nettoํㅜ Patricia Zach $^{1}$, Sonia Couto ${ }^{1}$ and Maria Teresa Zanella \\ ${ }^{1}$ Diabetes Education and Control Group-Kidney Hospital, Federal University of Sao Paulo, Brazil \\ ${ }^{2}$ Kidney and Hypertension Hospital, Federal University of Sao Paulo, Brazil
}

Submission: January 30, 2018; Published: October 10, 2018

*Corresponding author: Augusto Pimazoni-Netto, Diabetes Education and Control Group-Kidney Hospital, Federal University of Sao Paulo, Brazil, Email: pimazoni@uol.com.br

\begin{abstract}
Background: Compounded errors during insulin administration may impact the efficacy of diabetes control. Our major objective was to quantify the various errors committed by patients during insulin therapy.

Methods: This was a multicentric, observational study in which participants were asked to respond to a specific questionnaire under the supervision of a trained nurse, addressing problems and risks of insulin self-administration. The study included 140 individuals aged 6-75 years, with type 1 or type 2 diabetes on insulin for more than 6 months, allocated to adults or youth groups.

Results: Comparing performance of adults vs youth groups for withdrawal of 7 IU the rates of correct doses were $66.7 \%$ vs $100 \%$ with $30 \mathrm{U}$ syringes ( $\mathrm{p}=0.002) ; 70.8 \% \mathrm{vs} 95.0 \%$ with $50 \mathrm{U}$ syringes ( $\mathrm{p}=0.022)$; and $50.8 \% \mathrm{vs} 40.0 \%$ with $100 \mathrm{U}$ syringes $(\mathrm{p}=0.370)$, reflecting poor performance in both groups. With the target dose of $22 \mathrm{U}$, the rates of correct doses were $67.5 \% \mathrm{vs} 100 \%$ with $30 \mathrm{U}$ syringes ( $\mathrm{p}=0.003$ ); $66.7 \% \mathrm{vs} 95.0 \%$ with $50 \mathrm{U}$ syringes ( $\mathrm{p}=0.010)$; and $52.5 \% \mathrm{vs} 50.0 \%$ with $100 \mathrm{U}$ syringes $(\mathrm{p}=0.836)$, again reflecting poor performance in both groups with a higher dose. Other major errors included: improper rotation technique in $62.5 \%$ of patients; failure to lift a skinfold in $29.2 \%$; premature withdrawal of the needle from injection sites in $45.8 \%$; totally correct injection technique was documented in $10 \%$.

Conclusion: The results of the study point to the urgent need for implementation of effective educational strategies to provide patients with basic knowledge needed to minimize the potential risks of insulin self-administration, including use of appropriate insulin syringes according to size of injection dosage.
\end{abstract}

Keywords: Insulin therapy; insulin injection errors; insulin administration safety; diabetes treatment

\section{Introduction}

An overall assessment of glycemic control around the world shows that only a small fraction of patients with type 2 diabetes (DM2) achieve adequate glycemic control even after several years of treatment [1-4]. In Brazil, 73\% of patients with DM2 and no less than $90 \%$ of patients with type 1 diabetes (DM1) have poor glycemic control $(\mathrm{A} 1 \mathrm{C}>7 \%)$, as shown by a recent Brazilian multicenter study in 6,671 patients across several diabetes care centers throughout the country [1]. According to the Centers for Disease Control and Prevention, the percentage of adults with diabetes in the United States with $\mathrm{A} 1 \mathrm{C}>7 \%$ reached $43 \%$ during the period of 2003-2006 [5].

The growing population of people with diabetes has assumed epidemic proportions worldwide, with a consequent significant increase in the number of insulin users. At the same time, wrong information about correcttechniques of insulin self-administration is widespread and the consequences are highly worrying, since incorrect delivery results in substantial modification of the pharmacological action of insulin. This problem motivated a group of leading medical experts and diabetes educators to develop New Injection Recommendations for Patients with Diabetes, published in 2010 [6].

In patients with DM1 insulin therapy is an absolutely requirement. On the other hand, increasing number of patients with DM2 need insulin treatment when oral therapeutic options do not lead to desired glycemic control. However, resistance to initiating insulin treatment is frequent among physicians and patients with DM2, which slows or prevents the implementation of more intensive treatment regimens, with obvious negative consequences in terms of chronic complications of the disease. This refusal is mainly due to misbeliefs on the part of patients, which includes fear of insulin injections. When insulin is begun, this rejection is compounded by poor insulin administration techniques that need to be urgently addressed and overcome [7]. The condition known as "clinical inertia" applies when 


\section{Current Research in Diabetes \& Obesity Journal}

the patient's clinical conditions clearly indicate the need for intensification or adjustment of the therapeutic approach, but it is delayed-often for years in the case of insulin for DM2 [8]. A publication by the American Diabetes Association lists the most important myths and facts related to insulin administration [9].

The proper appreciation of the concept of "compounded error" is essential to understanding the increased risk represented by the combination of individual errors during insulin selfadministration. According to the Merriam-Webster dictionary the term "compound" refers to an error, condition or problem that makes any outcome even worse [10]. Inadequate guidance and patient compliance in relation to insulin self-administration are two of the major problem areas among the education initiatives in diabetes. In general, patients frequently receive a prescription for insulin with little, if any basic orientation on the correct techniques that will lead to successful treatment. The various technical errors committed by patients in insulin self-administration are already well-known to health care professionals but, to our knowledge, have never been properly quantified. The Diabetes Education and Control Group of the Kidney Hospital, Federal University of Sao Paulo-UNIFESP promoted and coordinated a multi-center study in order to identify and quantify the occurrence of technique errors during insulin self-administration [11].

\section{Material and Methods}

This was an observational, non-interventional study in which participants were asked to respond to a specific questionnaire addressing the main problems and potential risk factors related to insulin self-administration. In addition they were asked to perform a practical demonstration of how they withdraw various insulin doses from the vial into different syringes. The patients did not have to inject the selected insulin dose.
Patients of both sexes, on insulin for more than six months, aged 6-75 years receiving care at the Unified Health System (SUS) in the six participating centers were chosen at random. The study enrolled 140 individuals with type 1 or type 2 diabetes: the coordinating center included 40 individuals and each of the other five participating centers included 20 individuals. Patients were allocated to two groups: adults (120 individuals) and youth (20 children, adolescents and young adults with DM1). Nurses responsible for implementing the study questionnaire in the various centers received special training and were supervised by a medical professional in each participating center. The questionnaire contained 23 questions and practical observations on insulin injection technique outlining errors commonly made by patients (available at the appendix). The Study Protocol was approved by the Research Ethics Committees (ECs) of each participating center. The individuals included in the study or parents or legal guardians signed consent forms in the case of children and minors signed an informed consent to participate in the study, which was conducted consistent with Good Clinical Practice guidelines and the Declaration of Helsinki.

Primary objectives of the study included: to obtain information enabling a proper mapping of insulin self-administration practices in the public health service; to evaluate the adequacy of self-administration techniques used by patients; to evaluate the main problems and potential risk factors involved in insulin self-administration which may influence clinical outcomes and the safety of insulin treatment. Secondary objectives of the study included: to evaluate the demographics of a sample of 140 patients under insulin treatment; to obtain information on prescribed doses of intermediate, long- and short-acting insulins used by these patients.

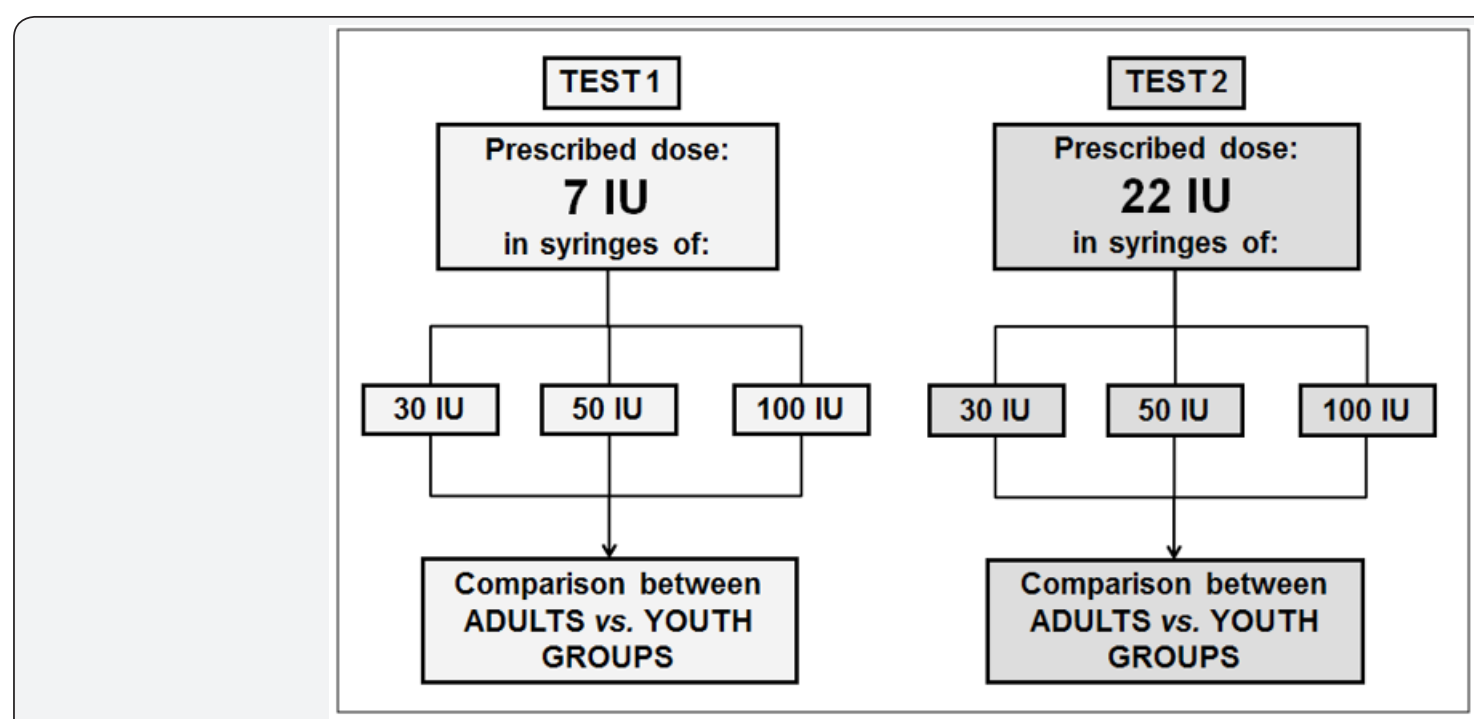

Figure 1: Testing patients' ability to withdraw the prescribed dose insulin from the vial.

The following parameters were evaluated by the attending nurse after patients' demonstration: rotation technique was assessed as correct or not; presence or absence of lipohypertrophy was evaluated by clinical examination; and grading of injection technique as correct, partially correct, or incorrect. Dose accuracy testing (acceptable variation $=$ prescribed insulin dose $\pm 1 \mathrm{IU}$ ) was conducted by assessing the patient>s ability to draw the correct doses of the prescribed insulin as directly observed by the nurse 


\section{Current Research in Diabetes \& Obesity Journal}

in charge. Initially, the patient was asked to draw up a dose of 7 IU of insulin, using 30 IU (1-unit scale markings), 50 IU (1-unit scale markings), and 100 IU syringes (2-units scale markings), manufactured by BD, Franklin Lakes, NJ, USA. Then, the same procedure was performed by the patient with a dose of $22 \mathrm{IU}$, using the same syringes, as shown in (Figure 1). The 7 IU testing dose was chosen for being a low and odd number and the 22 IU testing dose was chosen for being a higher, even dose so that accuracy was tested in two different situations.

\section{Statistical Analyses}

Categorical data were summarized by absolute and relative frequency of cases in relation to the total number of patients from the adults and youth groups. Data with a normal distribution of numeric and continuous parameters (e.g. ages) were summarized as mean and standard deviation in each group together with minimum, median and maximum values. Other parameters were evaluated by median and quartile values. Adults and youth groups were compared with respect to the percentage of patients who had correctly withdrawn the requested insulin doses from the vial, via the chi-square test. The statistical comparison of the number of patients who made mistakes in the withdrawn dose with $100 \mathrm{IU}$

Table 1: Summary of Patient Characteristics. syringes compared to the $30 \mathrm{IU}$ and $50 \mathrm{IU}$ syringes was performed using the McNemar test.

To check the characteristics of patients related to correct and incorrect doses, the chi-square test was used on categorical variables, and the Student's t test in the variables with numerical and continuous distribution. Statistical significance thresholds were set at $\mathrm{p}<0.05$. The data were obtained using the Minitab statistical software, version 16.1 .

\section{Study Results}

\section{Patient Characteristics}

(Table 1) shows the characteristics of patients with respect to demographics, diabetes-related data and insulin delivery practices in adults, youths, and in total group. An overview of the study population showed that two-thirds of the adults were DM2, with a slight preponderance of females. Adults were nearly 51 years of age on average, and youths, 15 years. Mean years since diagnosis for more than 10 years were 2.3 times more frequent in adults compared to youth. Considering the period of time of $>10$ years adults were 1.4 times more experienced with insulin therapy than the youth. Frequency of daily injections was higher in youth compared to adults.

\begin{tabular}{|c|c|c|c|c|c|c|}
\hline \multicolumn{7}{|c|}{ Summary of Patient Characteristics } \\
\hline & \multicolumn{2}{|c|}{ Adult } & \multicolumn{2}{|r|}{ Youth } & \multicolumn{2}{|c|}{ Total } \\
\hline & \multicolumn{2}{|c|}{$(n=120)$} & \multicolumn{2}{|r|}{$(n=20)$} & \multicolumn{2}{|c|}{$(n=140)$} \\
\hline \multicolumn{7}{|c|}{ 1. Type of Diabetes: N (\%) } \\
\hline Type 1 & 40 & $33.30 \%$ & 20 & $100.00 \%$ & 60 & $42.90 \%$ \\
\hline Type 2 & 80 & $66.70 \%$ & 0 & $0.00 \%$ & 80 & $57.10 \%$ \\
\hline \multicolumn{7}{|l|}{ 2. Gender: N (\%) } \\
\hline Female & 71 & $59.20 \%$ & 13 & $65.00 \%$ & 84 & $60.00 \%$ \\
\hline Male & 49 & $40.80 \%$ & 7 & $35.00 \%$ & 56 & $40.00 \%$ \\
\hline \multicolumn{7}{|l|}{ 3. Age (years) } \\
\hline mean $\pm \mathrm{sd}$ & \multicolumn{2}{|c|}{$50.9 \pm 17.1$} & \multicolumn{2}{|r|}{$15.0 \pm 6.1$} & \multicolumn{2}{|c|}{$45.8 \pm 20.4$} \\
\hline min.-med.-max. & \multicolumn{2}{|c|}{ 8-56-79 } & \multicolumn{2}{|r|}{$6-14-33$} & \multicolumn{2}{|c|}{$6-52-79$} \\
\hline \multicolumn{7}{|c|}{ 4. Time since Diabetes Diagnosis: N (\%) } \\
\hline$<1$ year & 4 & $3.30 \%$ & 0 & $0.00 \%$ & 4 & $2.90 \%$ \\
\hline 1 to 5 years & 13 & $10.80 \%$ & 7 & $35.00 \%$ & 20 & $14.30 \%$ \\
\hline 6 to 10 years & 20 & $16.70 \%$ & 7 & $35.00 \%$ & 27 & $19.30 \%$ \\
\hline$>10$ years & 83 & $69.20 \%$ & 6 & $30.00 \%$ & 89 & $63.60 \%$ \\
\hline \multicolumn{7}{|c|}{ 5. Time since starting Insulin Therapy: N (\%) } \\
\hline$<1$ year & 9 & $7.50 \%$ & 0 & $0.00 \%$ & 9 & $6.40 \%$ \\
\hline 1 to 3 years & 20 & $16.70 \%$ & 4 & $20.00 \%$ & 24 & $17.10 \%$ \\
\hline 3 to 5 years & 14 & $11.70 \%$ & 3 & $15.00 \%$ & 17 & $12.10 \%$ \\
\hline 5 to 10 years & 26 & $21.70 \%$ & 7 & $35.00 \%$ & 33 & $23.60 \%$ \\
\hline$>10$ years & 51 & $42.50 \%$ & 6 & $30.00 \%$ & 57 & $40.70 \%$ \\
\hline
\end{tabular}




\section{Current Research in Diabetes \& Obesity Journal}

6. Number of Insulin Injections per day: N (\%)

\begin{tabular}{|c|c|}
\hline 1 injection/day & 1 \\
\hline 2 injections/day & 4 \\
\hline 3 injections/day & 1 \\
\hline 4 injections/day & 1 \\
\hline${ }^{3} 5$ injections/day &
\end{tabular}

\begin{tabular}{c|c|c|c|c|c}
10 & $8.30 \%$ & 0 & $0.00 \%$ & 10 & $7.10 \%$ \\
\hline 44 & $36.70 \%$ & 1 & $5.00 \%$ & 45 & $32.10 \%$ \\
\hline 42 & $35.00 \%$ & 5 & $25.00 \%$ & 47 & $33.60 \%$ \\
\hline 13 & $10.80 \%$ & 13 & $65.00 \%$ & 26 & $18.60 \%$ \\
\hline
\end{tabular}

7. Type of Syringe used according to Graduation: $N(\%)$

\begin{tabular}{|c|}
\hline 30 IU \\
\hline 30 IU and $50 \mathrm{IU}$ \\
\hline $50 \mathrm{IU}$ \\
\hline 50 IU and $100 \mathrm{IU}$ \\
\hline $100 \mathrm{IU}$ \\
\hline $\begin{array}{c}\text { 8. Dose of intermediate / long acting Insulin per Injec- } \\
\text { tion: } \mathbf{N}(\%)\end{array}$ \\
\hline Up to $30 \mathrm{IU}$ \\
\hline 31 IU to $50 \mathrm{IU}$ \\
\hline$>50 \mathrm{IU}$ \\
\hline
\end{tabular}

\begin{tabular}{|c|c|c|c|c|c|}
\hline 5 & $4.20 \%$ & 10 & $50.00 \%$ & 15 & $10.70 \%$ \\
\hline 1 & $0.80 \%$ & 2 & $10.00 \%$ & 3 & $2.10 \%$ \\
\hline 41 & $34.20 \%$ & 8 & $40.00 \%$ & 49 & $35.00 \%$ \\
\hline 10 & $8.30 \%$ & 0 & $0.00 \%$ & 10 & $7.10 \%$ \\
\hline 63 & $52.50 \%$ & 0 & $0.00 \%$ & 63 & $45.00 \%$ \\
\hline
\end{tabular}

9. Dose of Regular / Rapid Insulin per Injection: N (\%)

\begin{tabular}{|c|}
\hline Up to $30 \mathrm{IU}$ \\
\hline don't use
\end{tabular}

\begin{tabular}{|c|c|c|c|c|c|}
\hline 74 & $61.70 \%$ & 15 & $75.00 \%$ & 89 & $63.60 \%$ \\
\hline 31 & $25.80 \%$ & 3 & $15.00 \%$ & 34 & $24.30 \%$ \\
\hline 15 & $12.50 \%$ & 2 & $10.00 \%$ & 17 & $12.10 \%$ \\
\hline
\end{tabular}

\begin{tabular}{|c|}
\hline 10. Evaluation of Rotation Technique: $\mathbf{N}(\mathbf{\%})$ \\
\hline Adequate \\
\hline Inadequate \\
\hline Don't practice rotation \\
\hline
\end{tabular}

\begin{tabular}{|c|c|c|c|c|c|}
\hline 79 & $65.80 \%$ & 20 & $100.00 \%$ & 99 & $70.70 \%$ \\
\hline 41 & $34.20 \%$ & 0 & $0.00 \%$ & 41 & $29.30 \%$ \\
\hline
\end{tabular}

\section{Time to needle withdraw after Insulin Injection: $\mathbf{N}$} (\%)

\begin{tabular}{|c|}
\hline Immediately \\
\hline Wait 5 seconds \\
\hline
\end{tabular}

\begin{tabular}{|c|c|c|c|c|c|}
\hline 34 & $28.30 \%$ & 12 & $60.00 \%$ & 46 & $32.90 \%$ \\
\hline 75 & $62.50 \%$ & 6 & $30.00 \%$ & 81 & $57.90 \%$ \\
\hline 11 & $9.20 \%$ & 2 & $10.00 \%$ & 13 & $9.30 \%$ \\
\hline
\end{tabular}

12. Skinfold use before Injection: $N(\%)$

\begin{tabular}{|c|c|c|c|c|c|c|}
\hline Yes & 85 & $70.80 \%$ & 17 & $85.00 \%$ & 102 & $72.90 \%$ \\
\hline No & 35 & $29.20 \%$ & 3 & $15.00 \%$ & 38 & $27.10 \%$ \\
\hline \multicolumn{7}{|c|}{$\begin{array}{l}\text { 13. Insulin Injection with Correct Angle }\left(45^{\circ} \text { or } 90^{\circ}\right) \text { : } \mathrm{N} \\
(\%)\end{array}$} \\
\hline Yes & 99 & $82.50 \%$ & 20 & $100.00 \%$ & 119 & $85.00 \%$ \\
\hline No & 21 & $17.50 \%$ & 0 & $0.00 \%$ & 21 & $15.00 \%$ \\
\hline \multicolumn{7}{|c|}{ 14. Presence of Lipohypertrophy: N (\%) } \\
\hline Yes & 23 & $19.20 \%$ & 10 & $50.00 \%$ & 33 & $23.60 \%$ \\
\hline No & 97 & $80.80 \%$ & 10 & $50.00 \%$ & 107 & $76.40 \%$ \\
\hline \multicolumn{7}{|c|}{$\begin{array}{l}\text { 15. Overall evaluation of the Insulin Injection Tech- } \\
\text { nique: } N(\%)\end{array}$} \\
\hline Totally correct & 12 & $10.00 \%$ & 12 & $60.00 \%$ & 24 & $17.10 \%$ \\
\hline Partially correct & 97 & $80.80 \%$ & 8 & $40.00 \%$ & 105 & $75.00 \%$ \\
\hline Totally incorrect & 11 & $9.20 \%$ & 0 & $0.00 \%$ & 11 & $7.90 \%$ \\
\hline
\end{tabular}




\section{Current Research in Diabetes \& Obesity Journal}

In the total group of our study population, the 100 IU syringes were being used by $45.0 \%$ of patients, the 50 IU syringes by $35.0 \%$ and the $30 \mathrm{IU}$ by just $10.7 \%$ of patients, respectively. Either $30 \mathrm{IU}$ or $50 \mathrm{IU}$ were used by $2.1 \%$ and either $50 \mathrm{IU}$ or $100 \mathrm{IU}$ were used by $7.1 \%$. Average doses up to $30 \mathrm{IU}$ of intermediate/long acting insulin and regular/rapid insulin were more frequent in both adults and youth. Inadequate rotation technique was twice more frequent in adults. Only 1/10 of adults and 1/10 of youth did not practice rotation. A high percentage of adults and youth performed skinfold before injections. Insulin injection with correct angle (45ㅇ or $90^{\circ}$ ) was a frequent practice both by adults and youth. Lipodystrophy was 2.6 times more frequent in youth, compared to adults. In the overall evaluation of insulin injection technique by the supervising nurse the percentage of youth practicing the correct technique was 6 times higher in youth than in adults.

\section{Correct and incorrect Insulin Doses withdrawn from the Vial}

Table 2: Correct and Incorrect Doses withdrawn from the Insulin Vial according to the Type of Syringe Utilized.

\begin{tabular}{|c|c|c|c|c|c|c|c|}
\hline \multicolumn{8}{|c|}{ Correct and Incorrect Doses withdrawn from the Insulin Vial according to the Type of Syringe Utilized } \\
\hline & \multicolumn{2}{|c|}{ Adults $(n=120)$} & \multicolumn{2}{|c|}{ Youth $(n=20)$} & \multicolumn{2}{|c|}{ Total $(n=140)$} & \multirow[b]{2}{*}{ p-value ${ }^{1}$} \\
\hline & $\mathrm{N}$ & $\%$ & $\mathrm{~N}$ & $\%$ & $\mathrm{~N}$ & $\%$ & \\
\hline \multicolumn{8}{|c|}{$\begin{array}{l}\text { 1. Dose withdrawn from the vial: } 7 \mathrm{IU} \text {; type of syringe } \\
\text { used: } 30 \mathrm{IU}\end{array}$} \\
\hline Correct & 80 & $66.70 \%$ & 20 & $100.00 \%$ & 100 & $71.40 \%$ & \multirow{2}{*}{0.002} \\
\hline Incorrect & 40 & $33.30 \%$ & 0 & $0.00 \%$ & 40 & $28.60 \%$ & \\
\hline \multicolumn{8}{|c|}{$\begin{array}{l}\text { 2. Dose withdrawn from the vial: } 7 \mathrm{IU} \text {; type of syringe } \\
\text { used: } 50 \mathrm{IU}\end{array}$} \\
\hline Correct & 85 & $70.80 \%$ & 19 & $95.00 \%$ & 104 & $74.30 \%$ & \multirow{2}{*}{0.022} \\
\hline Incorrect & 35 & $29.20 \%$ & 1 & $5.00 \%$ & 36 & $25.70 \%$ & \\
\hline \multicolumn{8}{|c|}{$\begin{array}{l}\text { 3. Dose withdrawn from the vial: } 7 \mathrm{IU} \text {; type of syringe } \\
\text { used: } 100 \mathrm{IU}\end{array}$} \\
\hline Correct & 61 & $50.80 \%$ & 8 & $40.00 \%$ & 69 & $49.30 \%$ & \multirow{2}{*}{0.37} \\
\hline Incorrect & 59 & $49.20 \%$ & 12 & $60.00 \%$ & 71 & $50.70 \%$ & \\
\hline \multicolumn{8}{|c|}{$\begin{array}{l}\text { 4. Dose withdrawn from the vial: } 22 \text { IU; type of sy- } \\
\text { ringe used: } 30 \mathrm{IU}\end{array}$} \\
\hline Correct & 81 & $67.50 \%$ & 20 & $100.00 \%$ & 101 & $72.10 \%$ & \multirow{2}{*}{0.003} \\
\hline Incorrect & 39 & $32.50 \%$ & 0 & $0.00 \%$ & 39 & $27.90 \%$ & \\
\hline \multicolumn{8}{|c|}{$\begin{array}{l}\text { 5. Dose withdrawn from the vial: } 22 \text { IU; type of sy- } \\
\text { ringe used: } 50 \mathrm{IU}\end{array}$} \\
\hline Correct & 80 & $66.70 \%$ & 19 & $95.00 \%$ & 99 & $70.70 \%$ & \multirow{2}{*}{0.01} \\
\hline Incorrect & 40 & $33.30 \%$ & 1 & $5.00 \%$ & 41 & $29.30 \%$ & \\
\hline \multicolumn{8}{|c|}{$\begin{array}{l}\text { 6. Dose withdrawn from the vial: } 22 \text { IU; type of sy- } \\
\text { ringe used: } 100 \mathrm{IU}\end{array}$} \\
\hline Correct & 63 & $52.50 \%$ & 10 & $50.00 \%$ & 73 & $52.10 \%$ & \multirow{2}{*}{0.836} \\
\hline Incorrect & 57 & $47.50 \%$ & 10 & $50.00 \%$ & 67 & $47.90 \%$ & \\
\hline
\end{tabular}

${ }^{1}$ Chi-square test used for the comparison between adults and youth.

Table 3: Number of Correct and Incorrect Doses Comparing the use of $30 \mathrm{IU}$ and $50 \mathrm{IU}$ Syringes to the Ratings of $100 \mathrm{IU}$ Syringes.

\begin{tabular}{|c|c|c|c|c|c|c|c|}
\hline \multicolumn{8}{|c|}{ Number of Correct and Incorrect Doses Comparing the use of $30 \mathrm{IU}$ and $50 \mathrm{IU}$ Syringes to the Ratings of $100 \mathrm{IU}$ Syringes } \\
\hline & & \multicolumn{2}{|c|}{ Adults } & \multicolumn{2}{|c|}{ Youth } & \multicolumn{2}{|c|}{ Total } \\
\hline & \multicolumn{2}{|c|}{$(n=120)$} & \multicolumn{2}{|c|}{$(n=20)$} & \multicolumn{2}{|c|}{$(n=140)$} & \\
\hline \multicolumn{8}{|l|}{ 1. Dose to be withdrawn: $7 \mathrm{IU}$} \\
\hline & \multicolumn{2}{|c|}{100 IU syringe } & \multicolumn{2}{|c|}{100 IU syringe } & \multicolumn{2}{|c|}{100 IU syringe } & \\
\hline & Correct & Incorrect & Correct & Incorrect & Correct & Incorrect & \\
\hline \multirow{2}{*}{ with 30 IU Syringe } & Correct & 50 & 30 & 8 & 12 & 58 & 42 \\
\hline & Incorrect & 10 & 29 & 0 & 0 & 10 & 29 \\
\hline & & \multicolumn{2}{|c|}{$\mathrm{p}^{1}=0.003$} & \multicolumn{2}{|c|}{$\mathrm{p}^{1}=0.001$} & \multicolumn{2}{|c|}{$\mathrm{p}^{1}<0.001$} \\
\hline
\end{tabular}




\section{Current Research in Diabetes \& Obesity Journal}

\begin{tabular}{|c|c|c|c|c|c|c|c|}
\hline \multirow{2}{*}{ with 50 IU Syringe } & Correct & 50 & 35 & 7 & 12 & 57 & 47 \\
\hline & Incorrect & 11 & 24 & 1 & 0 & 12 & 24 \\
\hline & & \multicolumn{2}{|c|}{$\mathrm{p}^{1}=0.001$} & \multicolumn{2}{|c|}{$\mathrm{p}^{1}=0.006$} & \multicolumn{2}{|c|}{$\mathrm{p}^{1}<0.001$} \\
\hline \multicolumn{8}{|c|}{ 2. Dose to be withdrawn: $22 \mathrm{IU}$} \\
\hline & \multicolumn{2}{|c|}{$100 \mathrm{IU}$ syringe } & \multicolumn{2}{|c|}{$100 \mathrm{IU}$ syringe } & \multicolumn{2}{|c|}{$100 \mathrm{IU}$ syringe } & \\
\hline & Correct & Incorrect & Correct & Incorrect & Correct & Incorrect & \\
\hline \multirow{2}{*}{ with 30 IU syringe } & Correct & 51 & 30 & 10 & 10 & 61 & 40 \\
\hline & Incorrect & 12 & 27 & 0 & 0 & 12 & 27 \\
\hline & & \multicolumn{2}{|c|}{$\mathrm{p}^{1}=0.009$} & \multicolumn{2}{|c|}{$\mathrm{p}^{1}=0.004$} & \multicolumn{2}{|c|}{$\mathrm{p}^{1}<0.001$} \\
\hline \multirow{2}{*}{ with 50 IU syringe } & Correct & 48 & 32 & 9 & 10 & 57 & 42 \\
\hline & Incorrect & 15 & 25 & 1 & 0 & 16 & 25 \\
\hline & & \multicolumn{2}{|c|}{$\mathrm{p}^{1}=0.020$} & \multicolumn{2}{|c|}{$\mathrm{p}^{1}=0.016$} & \multicolumn{2}{|c|}{$\mathrm{p}^{1}=0.001$} \\
\hline
\end{tabular}

${ }^{1}$ McNemar test used to evaluate significance of changes (correct and incorrect doses) comparing the $30 \mathrm{IU}$ and $50 \mathrm{IU}$ syringes to the precision of 100 IU syringes.

In relation to the precision in withdrawing the correct dose from the vial, the statistical comparison between adult and youth groups showed that young patients make less errors than adults when using 30 IU or 50 IU syringes, whether in drawing 7 IU dose ( $p=0.002$ for 30 IU syringe; $p=0.022$ for 50 syringe IU) or in drawing 22 IU dose ( $p=0.003$ and $p=0.010$ for 30 IU syringe and 50 IU syringe), but there is no significant difference when used syringes of $100 \mathrm{IU}(\mathrm{p}=0.370$ for the $7 \mathrm{IU}$ dose and $\mathrm{p}=0.836$ for the 22 IU dose) (Table 2). The superiority of 30 IU and 50 IU syringe in comparison to $100 \mathrm{IU}$ syringe in terms of accuracy in withdrawing the correct insulin dose is well stablished as seen in (Table 3).

It is also observed that for the $7 \mathrm{IU}$ dose the number of wrong doses increases significantly when using 100 IU syringes both among adults $(\mathrm{p}=0.003$ and $\mathrm{p}=0.001$, using the $30 \mathrm{IU}$ and $50 \mathrm{IU}$ syringe, respectively) and among youth $(\mathrm{p}=0.001$ and $\mathrm{p}=0.006$ using $30 \mathrm{IU}$ and $50 \mathrm{IU}$ syringes, respectively). Similar results were observed when the test dose of 22 IU was used (Table 3).

\section{Characteristics of patients who scored or missed the dose to be withdrawn}

Patients were classified according to their accuracy in drawing up the correct or incorrect insulin dose from the vial. A correct dose was defined as drawing up $7 \mathrm{IU} \pm 1 \mathrm{IU}$ and $22 \mathrm{IU} \pm 1 \mathrm{IU}$, regardless of the type of syringe used (30 IU, $50 \mathrm{IU}$ and $100 \mathrm{IU})$. If any dose was drawn incorrectly, it was considered «error» (Table 4).

Table 4: Patients' Performance according to their Ability to Withdraw Correct and Incorrect Insulin Dose from the Vial.

\begin{tabular}{|c|c|c|c|c|c|}
\hline \multicolumn{6}{|c|}{ Patients' Performance according to their Ability to Withdraw Correct and Incorrect Insulin Dose from the Vial } \\
\hline & \multirow{2}{*}{\multicolumn{2}{|c|}{$\begin{array}{c}\text { Correct dose }^{3} \\
(n=43)\end{array}$}} & \multirow{2}{*}{\multicolumn{2}{|c|}{$\begin{array}{c}\text { Incorrect dose }^{4} \\
(n=97)\end{array}$}} & \multirow{2}{*}{ p-value } \\
\hline & & & & & \\
\hline \multicolumn{6}{|l|}{ 1. Type of Diabetes: N (\%) } \\
\hline Type 1 & 29 & $67.40 \%$ & 31 & $32.00 \%$ & \multirow{2}{*}{$<0.001^{1}$} \\
\hline Type 2 & 14 & $32.60 \%$ & 66 & $68.00 \%$ & \\
\hline \multicolumn{6}{|l|}{ 2. Age (years) } \\
\hline Mean \pm sd. & & $38.0 \pm 18.9$ & & $9.2 \pm 20.2$ & \multirow{2}{*}{$0.002^{2}$} \\
\hline Min. - med. - max. & & 8-38-76 & & 6-57-79 & \\
\hline \multicolumn{6}{|l|}{ 3. Time since Diabetes Diagnosis: N (\%) } \\
\hline$£ 10$ years & 12 & $27.90 \%$ & 39 & $40.20 \%$ & \multirow{2}{*}{$0.163^{1}$} \\
\hline$>10$ years & 31 & $72.10 \%$ & 58 & $59.80 \%$ & \\
\hline 4. Time since starting Insulin Therapy: $N(\%)$ & & & & & \\
\hline
\end{tabular}




\section{Current Research in Diabetes \& Obesity Journal}

\begin{tabular}{|c|c|c|c|c|c|}
\hline$£ 10$ years & 17 & $39.50 \%$ & 66 & $68.00 \%$ & \multirow{2}{*}{$0.002^{1}$} \\
\hline$>10$ years & 26 & $60.50 \%$ & 31 & $32.00 \%$ & \\
\hline \multicolumn{6}{|c|}{ 5. Number of Insulin Injections per day: N (\%) } \\
\hline$<4$ injections / day & 28 & $65.10 \%$ & 74 & $76.30 \%$ & \multirow{2}{*}{$0.170^{1}$} \\
\hline${ }^{3} 4$ injections / day & 15 & $34.90 \%$ & 23 & $23.70 \%$ & \\
\hline \multicolumn{6}{|c|}{ 6. Type of Syringe used according to Graduation: N (\%) } \\
\hline $30 \mathrm{IU}$ and/or $50 \mathrm{IU}$ & 24 & $55.80 \%$ & 43 & $44.30 \%$ & \multirow{2}{*}{$0.210^{1}$} \\
\hline $100 \mathrm{IU}$ & 19 & $44.20 \%$ & 54 & $55.70 \%$ & \\
\hline \multicolumn{6}{|c|}{ 7. Dose of Intermediate / Long acting Insulin per Injection: N (\%) } \\
\hline Up to $30 \mathrm{IU}$ & 28 & $65.10 \%$ & 61 & $62.90 \%$ & \multirow{3}{*}{$0.423^{1}$} \\
\hline $31 \mathrm{IU}$ to $50 \mathrm{IU}$ & 8 & $18.60 \%$ & 26 & $26.80 \%$ & \\
\hline$>50 \mathrm{IU}$ & 7 & $16.30 \%$ & 10 & $10.30 \%$ & \\
\hline \multicolumn{6}{|c|}{ 8. Dose of Regular / Rapid Insulin per Injection: N (\%) } \\
\hline Up to $30 \mathrm{IU}$ & 35 & $81.40 \%$ & 64 & $66.00 \%$ & \multirow{2}{*}{$0.064^{1}$} \\
\hline Don't use & 8 & $18.60 \%$ & 33 & $34.00 \%$ & \\
\hline \multicolumn{6}{|l|}{ 9. Evaluation of Rotation Technique: N (\%) } \\
\hline Adequate & 22 & $51.20 \%$ & 24 & $24.70 \%$ & \multirow{2}{*}{$0.002^{1}$} \\
\hline Inadequate / don't practice rotation & 21 & $48.80 \%$ & 73 & $75.30 \%$ & \\
\hline \multicolumn{6}{|c|}{ 10. Time to Needle Withdraw after Insulin Injection: N (\%) } \\
\hline Immediately & 17 & $39.50 \%$ & 38 & $39.20 \%$ & \multirow{2}{*}{$0.968^{1}$} \\
\hline Wait 5 seconds & 26 & $60.50 \%$ & 59 & $60.80 \%$ & \\
\hline \multicolumn{6}{|l|}{ 11. Skinfold use Before Injection: N (\%) } \\
\hline Yes & 34 & $79.10 \%$ & 68 & $70.10 \%$ & \multirow{2}{*}{$0.271^{1}$} \\
\hline No & 9 & $20.90 \%$ & 29 & $29.90 \%$ & \\
\hline \multicolumn{6}{|c|}{ 12. Insulin Injection with Correct Angle $\left(45^{\circ}\right.$ or $\left.90^{\circ}\right)$ : $\mathrm{N}(\%)$} \\
\hline Yes & 38 & $88.40 \%$ & 81 & $83.50 \%$ & \multirow{2}{*}{$0.457^{1}$} \\
\hline No & 5 & $11.60 \%$ & 16 & $16.50 \%$ & \\
\hline \multicolumn{6}{|l|}{ 13. Presence of Lipohypertrophy: N (\%) } \\
\hline Yes & 12 & $27.90 \%$ & 21 & $21.60 \%$ & \multirow{2}{*}{$0.421^{1}$} \\
\hline No & 31 & $72.10 \%$ & 76 & $78.40 \%$ & \\
\hline \multicolumn{6}{|c|}{ 14. Overall Evaluation of the Insulin Injection Technique: N (\%) } \\
\hline Totally correct & 12 & $27.90 \%$ & 12 & $12.40 \%$ & \multirow{2}{*}{$0.024^{1}$} \\
\hline Partially or totally incorrect & 31 & $72.10 \%$ & 85 & $87.60 \%$ & \\
\hline
\end{tabular}

${ }^{1}$ Chi-square test ; ${ }^{2}$ Student's $t$ test; ${ }^{3}$ Correct dose in drawing the insulin dose from the vial (7 IU and $\left.22 \mathrm{IU}\right)$, with any of the syringes utilized (30 IU, $50 \mathrm{IU}, 100 \mathrm{IU})$; ${ }^{4}$ any error in terms of dose withdrawn from the vial (7 IU and/or $\left.22 \mathrm{IU}\right)$, with one or more syringes (30 IU, $\left.50 \mathrm{IU}, 100 \mathrm{IU}\right)$.

\section{Discussion}

Insulin self-administration is often done incorrectly, and this can lead to risks, especially when different types of errors occur simultaneously (compounded errors) [12,13]. These issues, summarized in (Table 1), can substantially modify the pharmacokinetics and pharmacodynamics of injected insulin, greatly increasing the risk of hypo-or hyperglycemia. Among the many errors occurring during self-administration of insulin, the most serious and unforeseen is the incorrect drawing up of doses from vials.

Despite rapid technological advances in insulin formulations over recent years, injection technique has not been given much attention in the management of injectable therapies [14]. Our study reveals a number of critical problems related to basics of insulin injection technique that may interfere with its expected pharmacological profile. Many problems can be avoided by adopting proper technique [6]. Theoretically, it should be expected that errors in insulin administration could be more frequent in patients who are less experienced with the disease and, more specifically, with the practice of insulin therapy.

(Table 4) shows the characteristics of patients according to correct or incorrect withdrawn dose. It can be observed that the type of diabetes (DM1 or DM2), age, time since start of therapy with insulin, the insulin administration rotation technique 


\section{Current Research in Diabetes \& Obesity Journal}

(proper / improper) are factors that correlate to correct or incorrect doses in withdrawing insulin dose. Patients who make more mistakes in withdrawing the insulin dose are older ( $\mathrm{p}=0.002)$, with DM2 ( $\mathrm{p}<0.001)$, who started insulin therapy less than 10 years ago $(p=0.002)$, and that do not use proper rotation technique or that do not rotate the insulin injection at all $(p=0.002)$. Patients that were considered by the supervising nurse as having poor insulin administration technique also made more errors than those with a totally correct approach to insulin injections $(p=0.024)$ (Table 4).

The results of the study also showed the higher performance? of $30 \mathrm{IU}$ and $50 \mathrm{IU}$ syringes for the prevention of a major problem in insulin self-administration. There is a substantial risk of withdrawing incorrect doses when using 100 IU syringes, which are graded by $2 \mathrm{IU}$, making it difficult the reading of syringe scale. The replacement of the 100 IU by 30 IU or 50 IU syringes, according to the needs of each patient, is an important preventive strategy to avoid technical errors in insulin self-administration, particularly for patients in the public health service who generally do not have access to educational programs which provide adequate guidance on the correct techniques for this procedure. To our knowledge, no other study approached this problem with the 100 IU syringes as a serious risk factor for in proper selection of insulin dose.

In the total group of our study population, the use of $100 \mathrm{IU}$ syringes was far more frequent than 50 IU syringes and 30 IU. If the 100 IU syringes are the least safe option for insulin injections, why not give preference to 30 IU or 50 IU syringes? The basic question is the average insulin injection individual doses to make sure that the volume of insulin utilized with the 100 IU syringes would fit the available volumes of 30 IU or 50 IU syringes. Our data show that a minority of our patients was using individual doses greater than 50 IU of NPH or long acting analogs and all of them were injecting less than $30 \mathrm{IU}$ of regular or short acting analogs or were not using short acting analogs at all. These data indicate that the vast majority of patients could be using $30 \mathrm{IU}$ or $50 \mathrm{IU}$ syringes instead of $100 \mathrm{IU}$ syringes. It should be noted that patients who take both NPH and regular insulins in our service do so with two separated injections instead of mixing in one single injection.

Table 5: Indications and Recommendations from the Brazilian Diabetes Society for the Choice of Needles to be Used with Syringes and Insulin Pens.

\begin{tabular}{|c|c|c|c|c|}
\hline \multicolumn{3}{|c|}{ Indications and Recommendations from the Brazilian Diabetes Society for the Choice of Needles to be Used with Syringes and Insulin } \\
Pens,18-21
\end{tabular}

The other critical finding of the study was that $67.2 \%$ of patients utilized improper rotation technique or did not rotate at all. The consequence of improper site rotation technique is the increased risk of lipohypertrophy, which is also related to increased frequency of reuse of insulin needles [15]. In our study, lipohypertrophy affected $23.6 \%$ of the study participants, but this may be an underestimation due to diagnostic difficulty in identifying small lipohypertrophy nodes (Table 1). Another recent study on the prevalence of lipohypertrophy showed that $64.4 \%$ of patient had this complication [16].

Another potentially problematic issue was the finding that a fair proportion of patients removed the needle immediately after The purpose of this dwell-time is to avoid reflux of insulin from the injection site. Use of skinfold and injection with a correct angle of $45^{\circ}$ or $90^{\circ}$ (according the clinical situation) for insulin administration was reported by the majority of patients.

\section{Study Limitations}

This study addressed several aspects relevant to the good practice of insulin self-administration. However, other key issues have not been properly surveyed, including the following:

1. The unequal distribution of participants between the adult group $(n=120)$ and the youth group $(n=20)$ may have an impact on the interpretation of statistical significance of differences found between the two groups. As shown in (Table 2)

2. Frequency and clinical impact of inadequate mixing of NPH insulin for complete resuspension. In a study of 109 patients using NPH insulin it was recommended that they should roll and tip the pen cartridge at least 20 times in order to get adequate insulin resuspension but, in fact, only $9 \%$ of these patients actually tipped and rolled the cartridges more than 10 times. As a consequence, NPH insulin concentration ranged from $5 \%$ to $214 \%$ and varied by more than $20 \%$ in $65 \%$ of the 109 patients [17]. Directions and recommendations for the use of needles for insulin syringes or pens are summarized in (Table 5), adapted from the Brazilian Diabetes Society - 2014-2015 guidelines [18] and other related papers [6,19-21]. the injection, without waiting the recommended 5-10 seconds. 


\section{Current Research in Diabetes \& Obesity Journal}

\begin{tabular}{|c|c|c|c|c|}
\hline \multirow[b]{2}{*}{$8 \mathrm{~mm}$} & \multirow[b]{2}{*}{ Adults } & \multirow[b]{2}{*}{ Indispensable } & $90^{\circ}$ or $45^{\circ}$ for adults & \\
\hline & & & $\begin{array}{l}45^{\circ} \text { children and ado- } \\
\text { lescents }\end{array}$ & \\
\hline $\begin{array}{c}12 \mathrm{~mm}, \\
12.7 \mathrm{~mm} \\
\text { and } 13 \mathrm{~mm}\end{array}$ & $\begin{array}{l}\text { RESTRICTED } \\
\text { INDICATION } \\
\text { FOR ALL PEO- } \\
\text { PLE }\end{array}$ & Indispensable & $45^{\circ}$ & High risk of intramuscular injection. \\
\hline
\end{tabular}

\section{Summary and Conclusion}

There are several obstacles and technical errors commonly observed in patients who practice self-administration of insulin, significantly increasing the likelihood of unsuccessful treatments [22-27]. The main topics that deserve full attention of the health team responsible for guiding the diabetic patient are summarized below:

1. Errors in insulin administration occur in clusters and in line with the concept of "compounded errors". Consequently, the final negative impact is greater than the sum of consequences of individual errors.

2. The myths that impair or impede the acceptance of insulin by diabetic patient should receive proper attention from health care team [28-30]. If this problem is not overcome, it will be almost impossible to implement safe and effective insulin therapy.

3. Although most of the study population already had experience with diabetes and insulin therapy for more than 10 years, the frequency of important technique errors during the study was a matter of deep concern.

4. Among all the observed problems, errors in the withdrawing of the prescribed dose from the insulin vial reached highly alarming proportions, since $50 \%$ of adults and $60 \%$ of younger patients drew up incorrect doses of insulin when using a $100 \mathrm{IU}$ syringes [31-33].

5. Although not included in the study objectives, it is important to note that the $12.7 \mathrm{~mm}$ long needles represent a high risk of intramuscular insulin injection and therefore should be quickly replaced by $8 \mathrm{~mm}$ needles (or preferably, $6 \mathrm{~mm}$ ) for syringe users and $4 \mathrm{~mm}$ or $5 \mathrm{~mm}$ for pen users [21].

6. Final message: the implementation of interdisciplinary groups of diabetes education is a key strategy to overcome the misinformation that is the biggest problem responsible for the high rate of uncontrolled diabetes $[34,35]$.

\section{Appendix}

Participating centers and respective local study coordinators of Multicentric Group for the Evaluation of Techniques of Insulin Administration:

1. Diabetes Education and Control Group (Sao Paulo Andrea Gallo, RN; Augusto Pimazoni-Netto, MD, PhD; Patricia Zach, MD; Sonia Couto, RN MSc; Maria Teresa Zanella, MD, $\mathrm{PhD}$ );
2. Taguatinga Regional Hospital, Brasilia (Hermelinda Pedrosa, MD; Maria Aparecida Caires Saigg, RN);

3. Diabetes; Endocrinology and Metabolism Unit, Clinical Hospital, Federal University of Parana (Rosangela Rea, MD; Rosangela Saalfeld Ataide, RN);

4. Institute for Children with Diabetes of Rio Grande do Sul, Porto Alegre (Balduino Tschiedel, MD; Paula Mondadori, RN); State Institute of Diabetes and Endocrinology;

5. Rio de Janeiro (Rosane Kupfer, MD; Rosa Vilarinho, RN);

Health Department of Jundiai City Hall (Augusto PimazoniNetto, MD, PhD; Nilce Boto Dompieri, RN).

\section{References}

1. Müller N, Schiel R, Osterbrink B, Holl RW, Kerner W, et al. (2008) Care and Outcome in Patients with Diabetes Mellitus Type 1 and Type 2 in Specialized Practice, Diabetes Specialized Hospital and Diabetes Department of a Regional General Hospital in Germany 2005. Diabetologia 3: 41-50.

2. Sämann A, Lehmann T, Heller T, Müller N, Hartmann P, et al. (2012) A retrospective study on the incidence and risk factors of severe hypoglycemia in primary care. Fam Pract 30(3): 290-293.

3. Horvath K, Jeitler K, Berghold A, Ebrahim SH, Gratzer TW, et al. (2007) Long-acting insulin analogues versus NPH insulin (human isophane insulin) for type 2 diabetes mellitus. Cochrane Database Syst Rev (2): CD005613.

4. (2009) Glinides in the treatment of diabetes mellitus type 2. Institute for Quality and Efficiency in Health Care, Germany, pp: 1-7.

5. Hemmingsen B, Schroll JB, Lund SS, Wetterslev J, Gluud C, et al. (2013) Sulphonylurea monotherapy for patients with type 2 diabetes mellitus. Cochrane Database Syst Rev (4): CD009008.

6. Badenhoop K, Bojunga J, Usadel HU (2003) Hypoglykämie. In: Mehnert H, Standl E, Usadel KH, Häring HU (Eds.), Diabetologie in Klinik und Praxis. Thieme, Germany.

7. Brückel J (2003) Hypoglykämie. In: Hrsg Böhm BO, Palitzsch KD, Rosak C, Spinas GA (Eds.), Klinische Diabetologie..

8. American Diabetes Association (2017) Standards of medical care in diabetes 2017. Diabetes Care 40 (suppl 1): 1-142.

9. European Agency for Evaluation of Medicinal Products (2012) Guideline on clinical investigation of medicinal products in the treatment or prevention of diabetes mellitus.

10. Clayton D, Woo V, Yale JF (2013) Canadian Diabetes Association 2013 Clinical Practice Guidelines for the Prevention and Management of Diabetes in Canada: Hypoglycemia. Can J Diabetes 37 (suppl 1): 69-71.

11. Whipple AO (1938) The surgical therapy of hyperinsulinism. J Internat Chir 3: 237-276.

12. Marks V (1976) The measurement of blood glucose and the definition of hypoglycemia. Horm Metab Res Suppl 6: 1-6. 
13. Bundesärztekammer (BÄK), Kassenärztliche Bundesvereinigung (KBV), Arbeitsgemeinschaft der Wissenschaftlichen Medizinischen Fachgesellschaften (AWMF). Nationale VersorgungsLeitlinie Therapie des Typ-2-Diabetes - Langfassung, 1. Auflage, Version 4, August 2013, zuletzt geändert November 2014.

14. Schumann M (2013) Electronic Medical Information System for longterm documentation of chronic diseases (EMIL).

15. The Diabetes Control and Complications Trial Research Group (1993) The effect of intensive treatment of diabetes on the development and progression of long-term complications in insulin-dependent diabetes mellitus. J Pediatr 125(2): 177-188.

16. Dulon M, Bardehle D, Blettner M (2003) Assessing social inequality in microcensus data and German national health examination survey. Gesundheitswesen 65(11): 629-635.

17. www.patientenschulungsprogramme.de

18. R Development Core Team (2010) R: A language and environment for statistical computing. R Foundation for Statistical Computing, Vienna, Austria.

19. Gallwitz B, Rosenstock J, Rauch T, Bhattacharya S, Patel S, et al. (2012) 2-year efficacy and safety of linagliptin compared with glimepiride in patients with type 2 diabetes inadequately controlled on metformin: a randomised, double-blind, non-inferiority trial. Lancet 380(9840): 475-483.

20. Nauck M, Frid A, Hermansen K, Thomsen AB, During M, et al. (2012) Long-term efficacy and safety comparison of liraglutide, glimepiride and placebo, all in combination with metformin in type 2 diabetes: 2-year results from the LEAD-2 study. Diabetes Obes Metab 15(3): 204-212.

21. Pramming S, Thorsteinsson B, Bendtson I, Binder C (1991) Symptomatic hypoglycaemia in 411 type 1 diabetic patients. Diabet Med 8(3): 217-222.

22. Kuniss N, Kramer G, Müller N, Kloos C, Wolf G, et al. (2016) History of mild hypoglycaemia does not affect the prevalence of diabetes-related distress in people with diabetes. Acta Diabetologica 53(5): 833-838.

23. Seaquist ER, Anderson J, Childs B, Cryer P, Dagogo Jack S, et al. (2013) Hypoglycemia and diabetes: a report of a workgroup of the American Diabetes Association and the Endocrine Society. J Clin Endocrinol Metab 36(5): 1384-1395.

24. Kulzer B, Seitz L, Kern W (2014) Real-world patient-reported rates of non-severe hypoglycaemic events in Germany. Exp Clin Endocrinol Diabetes 122(3): 167-172.
25. Ostenson CG, Geelhoed Duijvestijn P, Lahtela J, Weitgasser R, Markert Jensen M, et al. (2013) Self-reported non-severe hypoglycaemic events in Europe. Diabet Med 31(1): 92-101.

26. Donnelly LA, Morris AD, Frier BM, Ellis JD, Donnan PT, et al. (2005) Frequency and predictors of hypoglycaemia in Type 1 and insulintreated Type 2 diabetes: a population-based study. Diabet Med 22(6): 749-755.

27. UK Hypoglycaemia Study Group (2007) Risk of hypoglycaemia in types 1 and 2 diabetes: effects of treatment modalities and their duration. Diabetologia 50(6): 1140-1147.

28. Gold AE, MacLeod KM, Frier BM (1994) Frequency of severe hypoglycemia in patients with type I diabetes with impaired awareness of hypoglycemia. Diabetes Care 17(7): 697-703.

29. Wang PH, Lau J, Chalmers TC (1993) Meta analysis of the effects of intensive glycemic control on late complications of type I diabetes mellitus. Lancet 341(8856): 1306-1309.

30. The Diabetes Control and Complications Trial Research Group (1995) Adverse events and their association with treatment regimens in the diabetes control and complications trial. Diabetes Care 18(11): 14151427.

31. Kerner W, Freckmann G, Müller UA, Roth J, Schleicher E, et al. (2015) Position statement of the DDG working group for measurement of HbA1c. Diabetologie und Stoffwechsel 10(06): 329-333.

32. Müller Wieland D, Petermann A, Nauck M, Heinemann L, Kerner W, et al. (2016) Definition, Klassifikation und Diagnostik des Diabetes mellitus. Diabetologie 11(suppl 2): S78-S81.

33. Kloos C, Heller T, Böer K, Hunger Battefeld W, Wolf G, et al. (2011) Unnoticed shift in the normal range of glycated $\mathrm{HbA1c}$ with TOSOH high performance liquid chromatography. EASD Lisbon P985, Portugal.

34. Pani LN, Korenda L, Meigs JB, Driver C, Chamany S, et al. (2008) Effect of aging on $\mathrm{A} 1 \mathrm{C}$ levels in individuals without diabetes: evidence from the Framingham Offspring Study and the National Health and Nutrition Examination Survey 2001-2004. Diabetes Care 31(10): 1991-1996.

35. Roth J, Müller N, Lehmann T, Heinemann L, Wolf G, et al. (2016) HbA1c and age in non-diabetic subjects: an ignored association? Exp Clin Endocrinol Diabetes.
Your next submission with Juniper Publishers will reach you the below assets

- Quality Editorial service

- Swift Peer Review

- Reprints availability

- E-prints Service

- Manuscript Podcast for convenient understanding

- Global attainment for your research

- Manuscript accessibility in different formats

( Pdf, E-pub, Full Text, Audio)

- Unceasing customer service

Track the below URL for one-step submission https://juniperpublishers.com/online-submission.php 